Aim of the study: To investigate the expression status and association of $\beta$-catenin and AXIN2 in ameloblastoma. Material and methods: 30 ameloblastoma specimens and 10 normal oral mucosa tissues were enrolled in the study. The protein and RNA levels of $\beta$-catenin and AXIN2 were detected by immunohistochemistry staining, Western blot, and real-time PCR analysis. The relationship between $\beta$-catenin and AXIN2 protein and clinico-pathological parameters and prognosis was subsequently determined.

Results: The results show that $\beta$-catenin mRNA expression was 1.24 -fold higher in ameloblastomas than that in normal mucosa tissues, but AXIN2 mRNA expression was 0.47 -fold lower in ameloblastomas than that in normal mucosa tissues $(p<0.05)$. The Western blot results show that $\beta$-catenin and AXIN2 protein in ameloblastomas had a significantly higher level than normal mucosa tissues $(p<0.05)$. Immunohistochemical staining of $\beta$-catenin and AXIN2 protein in ameloblastoma was expressed at a higher level than normal oral mucosa $(p<0.05)$. Conclusions: AXIN2 and $\beta$-catenin play an important role in the tumorigenesis and progression of ameloblastoma.

Key words: ameloblastoma, $\beta$-catenin, AXIN2, Wnt pathway.

\section{Expression of $\beta$-catenin and AXIN2 in ameloblastomas}

\author{
Zhenhui Wei ${ }^{12}$, Ming Zhong ${ }^{1}$, Yan Guo ${ }^{3}$, Yan Wang ${ }^{4}$, Meisi Ren ${ }^{1}$, \\ Zhaoyuan Wang ${ }^{1}$
}

1Oral Pathology Department, Oral Medicine College of China Medical University, Shenyang, China 110001

2Dental Department, No. 463 Hospital of PLA, Shenyang, China 110001

${ }^{3}$ Center Laboratory, Oral Medicine College of China Medical University, Shenyang, China 110001

${ }^{4}$ Oral Internal Medicine Department, Oral Medicine College of China Medical University, Shenyang, China 110001

\section{Introduction}

Ameloblastoma is a relatively rare lesion, but one of the most common tumors with a histological resemblance to the enamel organ of the jaw bone. It accounts for approximately $36 \%$ of all odontogenic tumors in China [1]. As a slow-growing, persistent, and benign odontogenic epithelial tumor, it has the potential to behave aggressively at the local level and cause distant metastasis, with a high risk of recurrence (50-90\%) [2]. Although ameloblastomas are considered benign tumors, their clinical behavior occupies the middle ground between being benign and malignant. This tumor occurs most frequently (99.1\%) in the posterior region of the mandible [3], and causes an asymptomatic bulging of facial deformity, as well as infiltration and substantial destruction of local tissues. Its radiographic appearance is usually a well-defined unilocular or multilocular radiolucent lesion that can be associated with the crown of a nonerupted tooth.

Histologically, ameloblastoma is classified into subtypes of solid/multicystic, intraosseous, or unicystic, and peripheral $[4,5]$. The odontogenic epithelium within a background of fibrous stroma is characterized by prominent palisading of the basal cell nuclei (i.e., reverse polarization) and by vacuolization of the cytoplasm of the basal cells. Within the epithelial islands, stellate reticulumlike areas may be noted. Foci of squamous-like changes, granular cells, clear cells, and basaloid cells, as well as follicular, cystic, and plexiform patterns, provide clues to the histologic variants of this lesion [6].

Regarding histopathogenesis, ameloblastoma is thought to derive from the epithelial lining of a dentigerous cyst, from the remnants of the dental lamina, or from the basal layer of the oral mucosa [7]. Because the Wnt signaling pathway plays an essential role in tooth development, how the constituents of the pathway are expressed, including WNTs and their receptor and nuclear transcriptional factors, is regulated in a complex manner [8]. Evidence indicates that abnormal activation of the Wnt pathway plays an important role in tumor progression [9]. We have thus proposed that activation of the Wnt signaling pathway may contribute to ameloblastoma. To date, Wnt roles have been recognized in three distinct pathways: the canonical $\beta$-catenin pathway, the planar cell polarity pathway, and the Wnt Ca2+ pathway [10]. The canonical Wnt/ $\beta$-catenin pathway has been investigated in greater detail than the other two pathways, and it includes the adenomatous polyposis coli protein (APC), AXIN, and $\beta$-catenin. Of these, $\beta$-catenin is the key factor and functions as a transcriptional activator of the Wnt signaling pathway. Regulating its level and localization is central to mediating Wnt signals. Activation of the $\mathrm{Wnt} / \beta$-catenin pathway leads to inhibition of AXIN-mediated, $\beta$-catenin phos- 
phorylation, which thereby stabilizes $\beta$-catenin. The $\beta$-catenin thus accumulates and travels to the nucleus to form complexes with TCF/LEF and activates the Wnt target gene expression [11]. In the absence of the Wnt signal, $\beta$-catenin is subjected to phosphorylation and subsequent degradation via a multiprotein complex. The complex is organized by APC and AXIN1, or its homolog AXIN2, which serve as scaffolding components for the complex. Adenomatous polyposis coli, a tumor suppressor that is commonly mutated in cancer, is a cytoskeletal organizer for cell migration and a scaffold for GSK3 /CKI-mediated phosphorylation and degradation of the Wnt effector $\beta$-catenin [12]. The scaffolding protein AXIN, as a component of the degradation-mediating complex, is a potent negative regulator of Wnt signaling [13]. The functions of AXIN2 were first presented by Lammi et al. [14]. These authors presented the first evidence that mutations of AXIN2 are responsible for the severe oligodontia of affected patients, showing that AXIN2 function is essential for the development of dentition in humans. Because ameloblastoma is an odontogenic epithelial tumor, we presume that AXIN2 is related to ameloblastoma. The expression of AXIN2, however, has not been presented in ameloblastoma. This study therefore investigated the expression status and association of $\beta$-catenin and AXIN2 in ameloblastoma.

\section{Material and methods}

\section{Patients and tumor samples}

Thirty ameloblastoma specimens from 30 ameloblastoma patients from January 2004 to January 2009 were retrieved from odontogenic tumors of patients at the Department of Stomatology and Maxillofacial Surgery, School of Stomatology, China Medical University. Diagnosis and classification of all specimens were confirmed by histopathologic examination according to the World Health Organization's histological typing of odontogenic tumors (WHO 2005). The specimens were divided into three treatment groups. The first group was formalin-fixed and paraffin-embedded. Serial $4 \mu \mathrm{m}$ sections were cut from archived paraffin blocks and mounted on glass slides for immunohistochemical analysis. The second group was frozen in liquid nitrogen for RNA extraction and real-time PCR analysis. The third group was quick-frozen for Western blot analysis. Ten normal oral mucosa tissues were used as controls. All patients gave written informed consent.

\section{Total RNA isolation and cDNA synthesis}

Total RNA was isolated with Trizol from 30 ameloblastoma specimens and 10 normal oral mucosa tissues. RNA isolation was accomplished as follows: frozen $0.1 \mathrm{~g}$ tissue specimens were powdered and homogenized twice using a rotator-stator and a $23 \mathrm{G}$ needle after adding $1 \mathrm{ml}$ of TRIzol (Invitrogen, City, State, USA) in $1.5 \mathrm{ml}$ Eppendorf tubes and vortexing for about 15 to $30 \mathrm{~s}$. They remained in the homogenate for $5 \mathrm{~min}$ at room temperature. Residual protein was removed with $0.2 \mathrm{ml}$ of chloroform, mixed, capped securely, and vortexed for $15 \mathrm{~s}$, incubated for $3 \mathrm{~min}$ at room temperature, and centrifuged for $15 \mathrm{~min}$ at $12,000 \mathrm{~g}$ and $4^{\circ} \mathrm{C}$. We then transferred the upper aqueous phase $(0.5 \mathrm{ml})$, which contained RNA, to a new RNase-free tube. We added $0.5 \mathrm{ml}$ of isopropanol and mixed well by shaking, then incubated for 2 hours at $-20^{\circ} \mathrm{C}$.
Thereafter, the specimens were centrifuged for $15 \mathrm{~min}$ at $12,000 \mathrm{~g}$ and $4^{\circ} \mathrm{C}$. We discarded the supernatant and washed the RNA pellet with $1 \mathrm{ml}$ of $75 \%$ ethanol (in DEPCtreated water) by pre-cooling, oscillation, and mixing. It was then centrifuged again for $15 \mathrm{~min}$ at 7,500 g and $4^{\circ} \mathrm{C}$. We again discarded the supernatant and added $15 \mu$ l of nuclease-free water. Detecting $260 \mathrm{~nm}, 280 \mathrm{~nm}$ OD values with a UV-visible spectrophotometer, we saved the samples at $-80^{\circ} \mathrm{C}$. For the RNA concentration and purity check, we followed these steps: we took $1 \mu$ l of RNA sample and added $79 \mu$ l of DEPC water. After extracting the concentration, the purity of the RNA was determined by spectrophotometry (absorption at $260 \mathrm{~nm}$ and $280 \mathrm{~nm}$ ). The OD 260/280 ratio of the mRNA should be 1.8-2.0, suggesting that the RNA sample purity is qualified. The RNA $(\mu \mathrm{g} / \mu \mathrm{l})$ concentration $=\mathrm{OD} 260 \times 40 \times$ dilution factor/1,000. cDNA was synthesized from the total RNA with a High-Capacity cDNA Reverse Transcription Kit (Applied Biosystems, City, State, USA) according to the manufacturer's protocol.

\section{Real-time PCR gene expression analysis}

Real-time PCR was performed to measure the expression of $\beta$-catenin and AXIN2 mRNA in 30 ameloblastoma specimens and 10 normal oral mucosa tissues. The amplification was performed with an ABI7500 real-time PCR system (Applied Biosystems, USA). Real-time PCR assays using the SYBR Green I protocol (Takara, Japan) were carried out in micro-reaction tubes (Corbett Research, Mortlake, Australia) according to the manufacturer's instructions. The primers used to amplify $\beta$-catenin and AXIN2 are listed in Table 1. The primers were designed using Primer Express software Version 1.5 (Applied Biosystems, Foster City, CA, USA) and tested for their specificity by alignment using the BLASTN program, followed by the dissociation curve and primer efficiency tests. The $\beta$-actin gene was used as an internal control. PCR cycling was performed in a total volume of $20 \mu \mathrm{l}$, consisting of $10 \mu \mathrm{l}$ of $2 \times$ SYBR premix EX Taq buffer, $0.8 \mu \mathrm{l}$ of $10 \mu \mathrm{M}$ forward and $0.8 \mu \mathrm{l}$ of $10 \mu \mathrm{M}$ reverse primers, $0.4 \mu$ l of ROX Reference Dye, $2 \mu$ l of the sample cDNA, and $6 \mu$ l of $\mathrm{dH}_{2} \mathrm{O}$. The product was purified with a QIAquick Extraction kit (QIAGEN, Hilden, Germany), quantified with a spectrometer (PerkinElmer MBA2000, Fremont, CA, USA), and sequenced with an automated laser fluorescence sequencer (ABI PRISM 3100 Genetic Analyzer, Foster City, CA, USA). The known concentration of the product was serially diluted tenfold from $100 \mathrm{pg} / \mu \mathrm{l}$ to $0.1 \mathrm{pg} / \mu \mathrm{l}$. The dilution series of PCR products was used to establish the standard curve of realtime PCR. The real-time PCR conditions were 1 cycle at $95^{\circ} \mathrm{C}$

Table 1. Primers for CTNNB1, AXIN2, $\beta$-actin

\begin{tabular}{llll} 
Gene & Primer & Sequence $\left(5^{\circ}-3^{*}\right)$ & bp \\
CTNNB1 & $\begin{array}{l}\text { Forward } \\
\text { Reverse }\end{array}$ & $\begin{array}{l}\text { CAAGTGGGTGGTATAGAGG } \\
\text { GGGATGGTGGTGTAAG }\end{array}$ & 226 \\
AXIN2 & $\begin{array}{l}\text { Forward } \\
\text { Reverse }\end{array}$ & $\begin{array}{l}\text { GACGGACAGCAGTGTAGATG } \\
\text { GGGTCTCGGGAATGA }\end{array}$ & 151 \\
\hline -actin & $\begin{array}{l}\text { Forward } \\
\text { Reverse }\end{array}$ & AGTTGCGTTACACCCTTTC & 492 \\
& TGTCACCTTCACCGTTCC & \\
\hline
\end{tabular}


for $30 \mathrm{~s}$, followed by 40 cycles of $5 \mathrm{~s}$ at $95^{\circ} \mathrm{C}$ for denaturation, $34 \mathrm{~s}$ at $60^{\circ} \mathrm{C}$ for annealing, and $15 \mathrm{~s}$ at $72^{\circ} \mathrm{C}$ for extension. The melting program was performed at $72^{\circ} \mathrm{C}$ to $95^{\circ} \mathrm{C}$ with a heating rate of $1^{\circ} \mathrm{C}$ per every $45 \mathrm{~s}$. Spectral data were captured and analyzed using Rotorgene Real-Time Analysis Software. All samples were run in triplicate. $\beta$-actin was applied as an endogenous RNA reference gene. Gene expression was normalized to the expression of $\beta$-actin.

Quantification was completed using the comparative Ct method [15]. The housekeeping gene $\beta$-actin was used to normalize the CTNNB1 and AXIN2 gene expression to correct for the amount of total RNA added and the amount of the inhibitor during the reverse transcription process. Relative gene expression data were normalized against $C t$ values for the housekeeping $\beta$-actin gene, and the fold change $(2-\Delta \Delta \mathrm{Ct})$ was determined by comparing with average expression levels for the control samples, with the index defined as 1.0. Each expression assay was repeated three times.

\section{Western blot analysis}

The target protein was detected from 30 ameloblastoma specimens and 10 normal oral mucosa tissues using Western blot analysis. Appropriate frozen tissue samples were collected and homogenized in $2 \times$ lysis buffer $(50 \mathrm{mM}$ Tris- $\mathrm{HCl}$, $\mathrm{pH}$ 7.6, $150 \mathrm{mM} \mathrm{NaCl}, 10 \mathrm{mM} \mathrm{CaCl}_{2}$, and 1\% Triton X-100, $0.02 \% \mathrm{NaN}_{3}$ ) and centrifuged for $1 \mathrm{~h}$ at $12,000 \mathrm{~g}$ and $4^{\circ} \mathrm{C}$. Supernatants were isolated and protein concentrations were determined using a BCA protein assay. After measuring protein concentration, the protein was heated for 5 min at $98^{\circ} \mathrm{C}$ and loaded onto sodium dodecyl sulfate PAGE (SDS-PAGE; 8-10\% acrylamide). After separation, the protein was electrophoretically transferred onto a nitrocellulose membrane. The membrane was blocked and incubated for $1 \mathrm{~h}$ with 3\% nonfat dry milk at room temperature, subsequently probed with the primary antibodies anti- $\beta$-catenin $(1: 100$ rabbit polyclonal antibody, Abcam, Cambridge, UK) and anti-AXIN2 (1: 400 rabbit polyclonal antibody, Santa Cruz Biotechnology, Santa Cruz, CA, USA), with $\beta$-tubulin used as a loading control. Antibodies were incubated for $1 \mathrm{~h}$ at room temperature and overnight at $4^{\circ} \mathrm{C}$. The membrane was then washed and incubated by alkaline phosphatase-conjugated anti-rabbit secondary antibodies $(1: 5,000)$ at room temperature and visualized with the Protein Detector BCIP/NBT Western Blot Kit (KPL, Gaithersburg, MD, USA) following the manufacturer's instructions. The results were measured as the gray value using automatic electrophoresis (UVP GDS8000, Bio-Rad, USA).

\section{Immunohistochemical staining}

Immunohistochemical staining was performed using the standard streptavidin-peroxidase (SP) method with the UltraSensitive TM S-P Kit (Maixin-Bio, China) according to the manufacturer's instructions, and signals were visualized using the DAB substrate, which stains the target protein yellow. Briefly, one paraffin-embedded block of the tissue was cut at $4 \mu \mathrm{m}$ and placed on poly-L-lysine coated slides. The slides were deparaffinized in xylene, rehydrated in a gradient of ethanol solutions, and then immersed in $10 \mathrm{mM}$ sodium citrate buffer ( $\mathrm{pH}$ 6.0), which was pretreated in a microwave oven for 10 min, followed by a 10-min rinse with phosphatebuffered saline (PBS). The sections were incubated with 3\% hydrogen peroxide for 10 min to block endogenous peroxidase activity at room temperature. Nonspecific reactions were blocked by incubating the sections in a solution containing normal serum. Then, the slides were incubated in a humid chamber at $4^{\circ} \mathrm{C}$ overnight with primary antibodies: anti- $\beta$ catenin (1: 100 rabbit polyclonal antibody, Abcam, Cambridge, UK) and anti-AXIN2 (1: 50 rabbit polyclonal antibody, Santa Cruz Biotechnology, Santa Cruz, CA, USA). After being rinsed with PBS, slides were incubated with a secondary antibody followed by streptavidin-biotin-peroxidase complex, both for 30 min at room temperature with a PBS rinse between each step (LSAB+ system; DakoCytomation, USA). The slides were incubated with diaminobenzidine- $\mathrm{H}_{2} \mathrm{O}_{2}$ (DAB+ system; DakoCytomation), then rinsed with distilled water and counterstained with hematoxylin. Finally, they were dehydrated through graded alcohols to xylene and cover slipped. The sections were prepared for microscopic observation. The positive control of $\beta$-catenin was human colorectal cancer section and positive control of AXIN2 was seminiferous duct cells supplied by Maixin-Bio company. Negative controls consisted of tissue sections incubated with PBS (0.01 mol/l) instead of the primary antibody.

Evaluation of immunohistochemical staining scores was performed via microscopic analysis by two independent observers blinded for patient outcome, each of whom provided a consensus opinion of stain patterns. Immunohistochemical staining of cells for $\beta$-catenin and AXIN2 was scored according to stain intensity and extent of cells stained by semi-quantitative evaluation [16]. Brown-yellow staining observed mainly in cell plasma and cell nucleus was considered positive for $\beta$-catenin and AXIN2 protein expression. Stain intensity was graded using a 4-point scale: 0 = no staining; 1 = weak-yellow; 2 = brown-yellow; and 3 = brown-black. The extent of positive cells, defined as the percentage of positive staining areas of tumor cells or normal oral mucosa epithelial cells in relation to the entire tissue area, was scored using a semiquantitative 5-point scale as follows (100 cells were counted by two independent observers, who did not know the clinicopathological features of these LIC): $0=$ negative stained cells; $1=$ positive stained cells $\leq 10 \% ; 2$ = positive stained cells from 11 to $50 \%$; $3=$ positive stained cells 51 to $80 \%$; and $4=$ positive stained cells $>80 \%$. The final immunoreactive score (IRS) was determined by multiplying the intensity and extent of positive scores, yielding a range from 0 to 12 . Based on semiquantitative integral evaluation, the immunohistochemical results with an IRS of $\beta$-catenin and AXIN2 were divided into four groups: scores 0 to 2 were defined as negative expression $(-)$; 3 to 5 as weak staining (+); 6 to 8 as moderate staining $(++)$; and 9 to 12 as strong staining $(+++)$. Staining scores of 0 to 5 and 6 to 12 were considered to be low and high expression, respectively.

\section{Statistical analysis}

All statistical analyses were carried out using SPSS 13.0 statistical software. In the real-time PCR analysis, one-way ANOVA was used to analyze the significance of mRNA expres- 
sion between ameloblastoma and normal oral mucosa tissues. For the immunohistochemical results, the Pearson $\chi^{2}$ test was used to analyze the expression. P values of $<0.05$ were considered statistically significant.

\section{Results}

Expression of $\beta$-catenin and AXIN2 mRNA in ameloblastoma and normal oral mucosa

The expression of CTNNB1 ( $\beta$-catenin) mRNA and AXIN2 mRNA was detected in 30 ameloblastomas and 10 normal oral mucosa samples using real-time PCR amplification. The $\Delta \Delta \mathrm{Ct}$ method was used to calculate the CTNNB1 and AXIN2 expression level relative to the control. The amplification curve and dissociation curve of the two genes indicate the specificity of the product (Fig. 1). CTNNB1 and AXIN2 CT values were calculated using Rotorgene Real-Time Analysis Software, and relative gene expression data were normalized against Ct values for the housekeeping $\beta$-actin gene. The fold change $(2-\Delta \Delta \mathrm{Ct})$ was determined by comparing average expression levels with the control samples; that is, $2-\Delta \Delta C T$ defines the relative expression change of the target gene in the tumor samples relative to normal mucosa tissue. The results show that CTNNB1 mRNA expression was 1.24-fold higher in ameloblastomas compared to that in normal mucosa tissues (Table 2), but AXIN2 mRNA expression was downregulated, and 0.47-fold lower in ameloblastomas compared to that in normal mucosa tissues (Table 3).

Expression of $\beta$-catenin and AXIN2 protein in ameloblastoma and normal oral mucosa

The Western blot results show that $\beta$-catenin and AXIN2 in ameloblastomas have significantly more protein compared to normal mucosa tissues $(p<0.05)$. There were no evident differences, however, among the kinds of ameloblastomas $(p>0.05)$ (Table 4, Fig. 2).
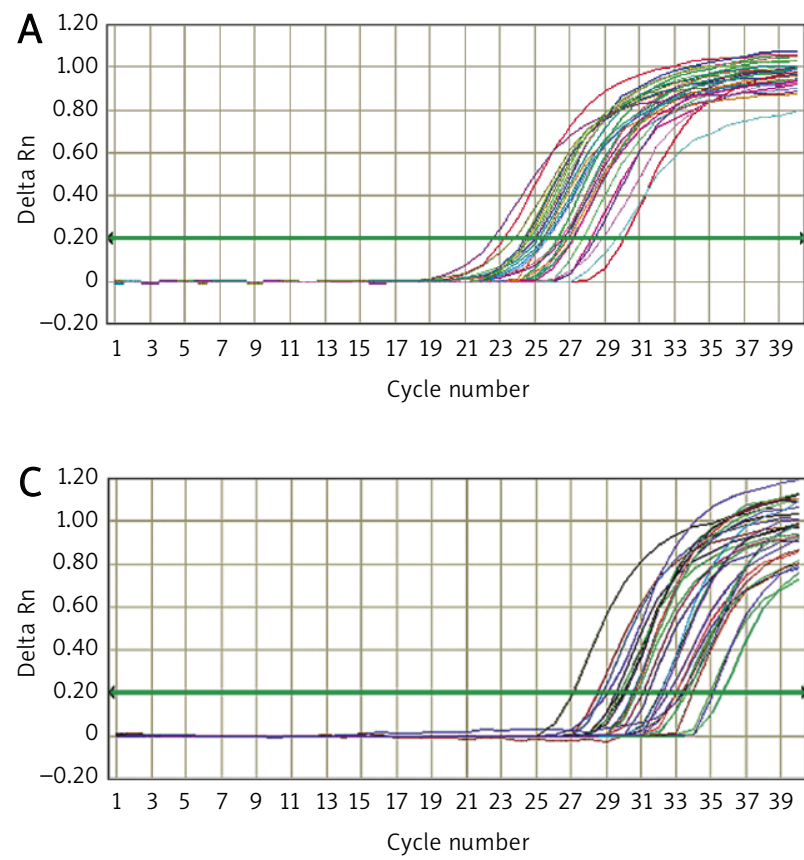

Immunohistochemical staining of $\beta$-catenin and AXIN2 protein in ameloblastoma and normal oral mucosa

Immunoreactivity for $\beta$-catenin was detected in the cytoplasm and occasionally in the nucleus of nearly all the stellate reticulum cells and peripheral columnar cells of ameloblastomas (Fig. 3A and B). Finally, all the 30 ameloblastomas were found to have $\beta$-catenin positive expression in the cytoplasm, along with eight cases with $\beta$-catenin positive expression in the nucleus. $\beta$-catenin was expressed in the normal oral mucous membrane, with no aberrant expression in cytoplasm and nucleus (Fig. 3C). Immunoreactivity for AXIN2 was detected in the cytoplasm and occasionally in the nucleus of nearly all the stellate reticulum cells and peripheral columnar cells of the ameloblastomas (Fig. 3D and E). Only weak staining was detected in the cytoplasm of normal oral mucosa cells (Fig. 3F).

\section{Discussion}

$\beta$-catenin, originally isolated by its association with the cytoplasmic domain of the cell adhesion molecule cadherin, has a signaling role in the Wnt pathway to control cellular proliferation or cell death [17].

Research has found that the aberrant expression of $\beta$-catenin exists in many tumors, but aberrant expression modes differ. In colorectal cancer, hepatocellular carcinoma, and melanoma, the expression of $\beta$-catenin inside the cells increases [18], whereas in the cell membrane of esophagus cancer, breast cancer, and other cancers the expression decreases [19]. The two aberrant expression modes thus show that $\beta$-catenin plays different roles in cancer development. The increased expression of $\beta$-catenin in the cytoplasm of tumors in the early stage of the disease suggests that the
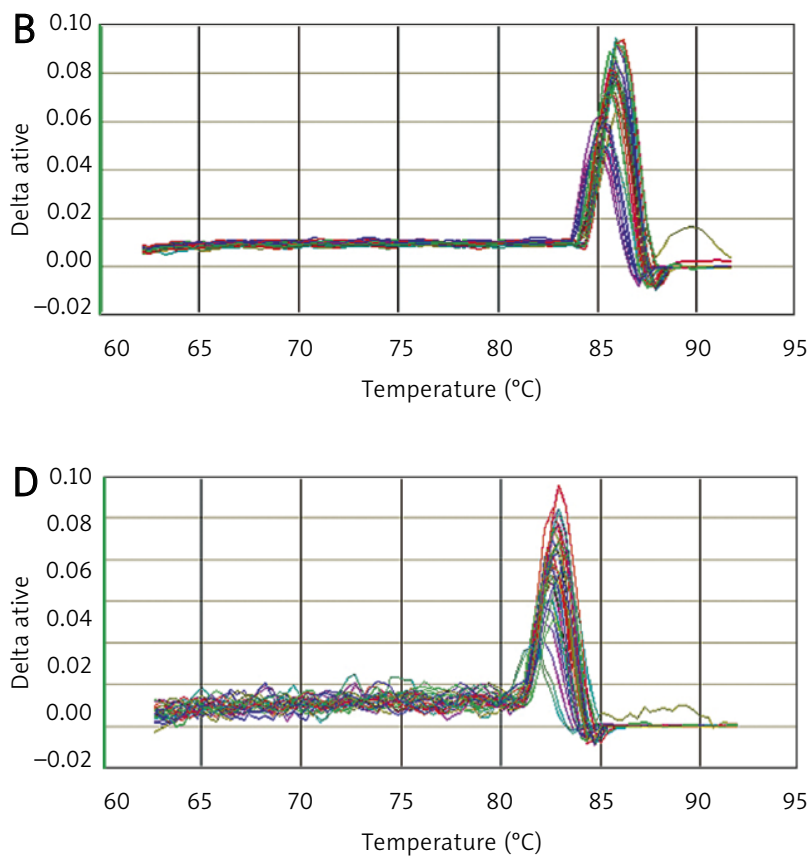

Fig. 1. Amplification and dissociation curves detected by real-time P(R; A) CTNNB1 amplification; B) CTNNB1 dissociation; C) AXIN2 amplification; D) AXIN2 dissociation curve 
Table 2. The mRNA expression level of CTNNB1 mRNA detected in ameloblastomas compared to mucosa tissues

$\begin{array}{llll}\text { Samples } & \Delta \mathrm{Ct} & \Delta \boldsymbol{C} \mathrm{Ct} & 2-\Delta \mathrm{CT} \\ \text { Ameloblastomas } & 3.17 \pm 0.19 & & \\ \text { Mucosa tissues } & 3.48 \pm 0.28 & -0.31 \pm 0.19 & 1.24(0.92 \sim 1.41)\end{array}$

Notes: ${ }^{\Delta} C t=[C t(\beta$-catenin $)]-[C t(\beta$-actin $)] ;{ }^{\Delta} C t=\left[{ }^{\Delta} C t(A B s)\right]-\left[{ }^{\Delta} C t\right.$ (normal mucosa tissues)]

Table 3. The mRNA expression level of AXIN2 in ameloblastomas compared to mucosa tissues

$\begin{array}{llll}\text { Samples } & \Delta \mathrm{Ct} & \Delta \Delta \mathrm{Ct} & 2-\Delta \Delta \mathrm{CT} \\ \text { Ameloblastomas } & 8.79 \pm 0.25 & & \\ \text { Mucosa tissues } & 7.70 \pm 0.35 & 1.09 \pm 0.25 & 0.47(0.40 \sim 0.56)\end{array}$

Notes: ${ }^{\Delta} C t=[C t(A X I N 2)]-[C t(\beta$-actin $)] \Delta \Delta C t=\left[{ }^{\Delta} C t(A b s)\right]-\left[{ }^{\Delta} C t(\right.$ normal mucosa tissues)]

Table 4. Expression of -catenin and AXIN2 protein in ameloblastoma compared to mucosa tissues

$\begin{array}{llll}\text { Samples } & n & \boldsymbol{\beta} \text {-catenin } & \text { AXIN2 } \\ \text { Ameloblastomas } & 30 & 0.65 \pm 0.57^{*} & 1.15 \pm 0.93^{*} \\ \text { Mucosa tissues } & 10 & 0.08 \pm 0.05 & 0.28 \pm 0.11\end{array}$

${ }^{*} p<0.05$ (ameloblastomas vs. mucosa tissues)

protein may be related to the occurrence of the tumor, because abnormal accumulation of cytoplasmic $\beta$-catenin can lead to cell proliferation. Indeed, if $\beta$-catenin expression in the lateral membrane of the tumor cell decreases, its invasive ability can be enhanced by affecting the role of cell adhesion, which is related to tumor development.

Hassanein et al. [20] conducted immunohistochemical analysis of $\beta$-catenin expression in pilomatricoma, craniopharyngioma, and calcifying odontogenic cyst (COC). Their results show that $\beta$-catenin has strong positive expression in the membrane, cytoplasm, and nucleus of immature basaloid cells. As such, the increase of drift $\beta$-catenin may activate downstream factors of these cells' Wnt signal pathway, induce extensive cell proliferation, reduce apoptosis, and cause the loss of cell metabolism balance. Therefore, it plays an important role in the occurrence of the tumor. Shigeki et al.
[21] compared the $\beta$-catenin expression in COC and ameloblastoma, respectively, to find that all patients' nucleus and cytoplasm have heterologous expression. They thus inferred that the accumulation mechanism of $\beta$-catenin in cytoplasm and nucleus could be related to the activation of the Wnt signaling pathway.

In this study, we have presented evidence of $\beta$-catenin mRNA and protein expression in ameloblastomas using the real-time PCR method, Western blot analysis, and immunohistochemistry. Similar to Hassanein et al. [20], our results indicate that $\beta$-catenin is expressed higher at both mRNA and protein levels in ameloblastoma tissues compared to normal oral mucosa tissues. This suggests that $\beta$-catenin is involved in the pathogenesis of ameloblastomas. To analyze what causes the upregulation, we further analyzed the members of the degradation complex.

We know that in the entire process of Wnt signal transmission, the formation of compounds is a necessity that induces phosphorylation of $\beta$-catenin and causes it to degrade, thus inhibiting this pathway. $\beta$-catenin is the positive regulatory factor of the pathway of Wnt signal transmission, whereas APC protein, GSK-3, and AXIN are negative regulatory factors [22]. It has been shown in mice that AXIN2 exhibits tissue- and stage-specific expression patterns during development [23]. It is expressed in the primitive streak and later in the dorsal neural tube and developing somites, as well as in the branchial arches and limb buds of mouse embryos [24]. It is interesting that AXIN2 expression is induced by Wnt signaling, suggesting a suppressing role for AXIN2 through a negative feedback loop.

Lammi et al. [14] presented the first evidence that AXIN2 function is essential for the development of dentition in humans. They studied the expression of AXIN1 and AXIN2 during mouse tooth development by in situ hybridization. AXIN1 was expressed uniformly in the developing jaws, whereas AXIN2 expression was most intense in the mesenchyme underlying the oral and dental epithelium. At more advanced stages of tooth morphogenesis, the expression was intense in the odontoblasts producing dentine. AXIN2 expression was also seen in the enamel knot, an epithelial signaling center that regulates tooth morphogenesis [25]. This further proved the tissue and phase specificity of the expression of AXIN2, whose abnormal expression may cause abnormal tooth development.
A

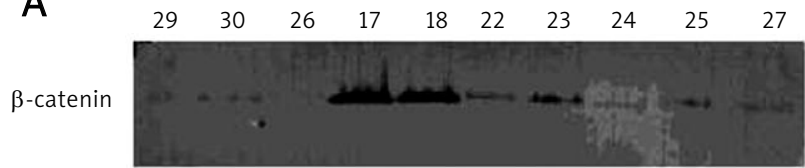

$\beta$-tubulin

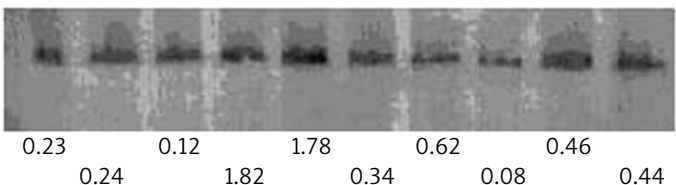

B

AXIN2

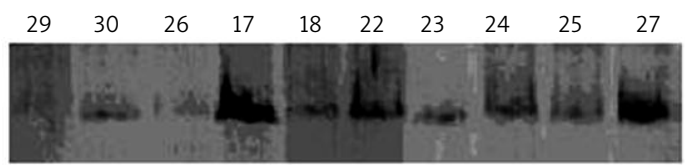

$\beta$-tubulin
AXIN2/
$\beta$-tubulin

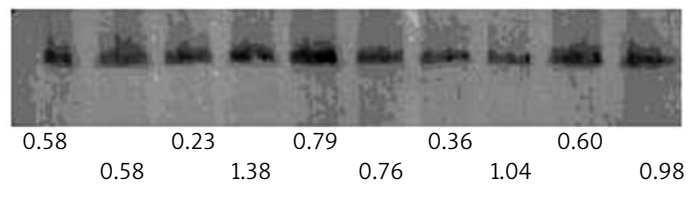

Fig. 2. A) $\beta$-catenin expression level detected by Western blot analysis. The figures below the gel image represent the ratios of $\beta$-catenin to $\beta$-tubulin; B) AXIN2 expression level detected by Western blot analysis. The figures below the gel images represent the ratios of AXIN2 to $\beta$-tubulin 

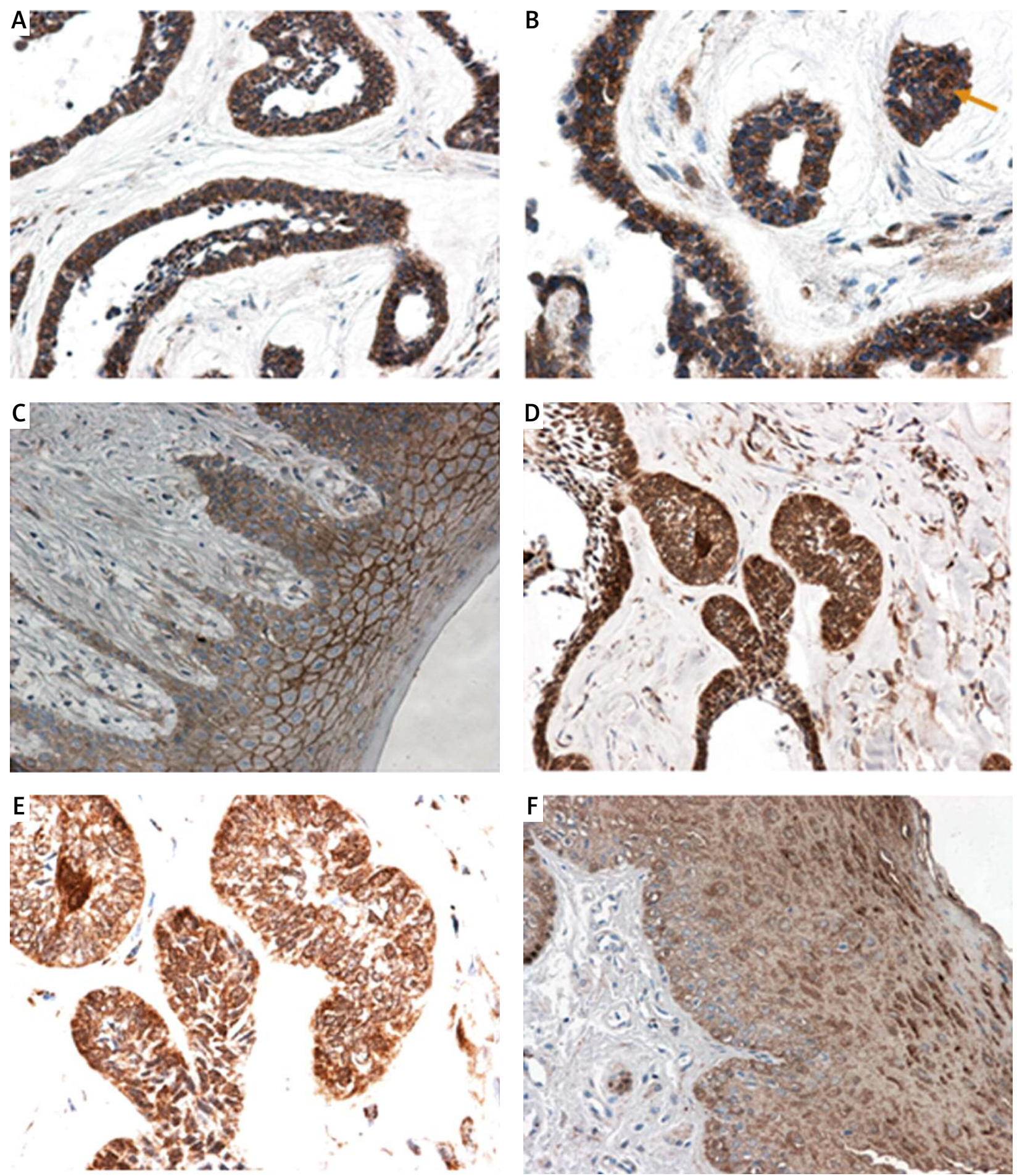

Fig. 3. A) $\beta$-catenin aberrant expression in cytoplasm of ameloblastomas (20x); B) $\beta$-catenin aberrant expression in the nucleus of ameloblastomas (arrow) (40x); C) $\beta$-catenin expressed in the normal oral mucous membrane, with no aberrant expression in cytoplasm and nucleus (20x); D) AXIN2 is expressed in ameloblastomas (20x); E) AXIN2 is expressed in ameloblastomas (40x); F) AXIN2 is expressed in the normal oral mucous membrane $(20 x)$

Because ameloblastomas are an odontogenic epithelial tumor, AXIN2 plays an important role in tooth development. We presume that AXIN2 is related to ameloblastoma. Therefore, in this study, we further analyzed AXIN2 mRNA and protein expression in ameloblastomas by real-time RT-PCR, Western blot, and immunohistochemistry. By applying the Western blot method, this experiment analyzed 30 exam- ples and found that the expression of protein in ameloblastomas is obviously higher than that of the normal mucous membrane, but the expression of mRNA is opposite. This is different from the results of several other research reports [26], which indicates that the increased expression of AXIN2 is not a result of the improvement of its transcriptional level. We then applied the SABC method to further analyze 
the expression of AXIN2, which showed that it has strong expression in the cytoplasm and the cell nucleus of tumor cells. The result of the expression is clearly positive because AXIN2 is the target gene regulated by $\beta$-catenin-TCF [27]. Thus, we can infer that this results from the abnormal expression of $\beta$-catenin. When it enters into the nucleus and combines with TCF, it activates AXIN2 and enables AXIN2 to transcribe, causing abnormal expression and creating negative feedback inhibition in the Wnt signaling pathway.

The results indicate that AXIN2 is expressed lower at the mRNA level, but expressed higher at the protein level in ameloblastoma tissues compared to normal oral mucosa tissues. As especially seen by immunohistochemical staining, in the case of $\beta$-catenin abnormal expression, AXIN2 also had obviously higher expression. In the Wnt signal, however, AXIN2 is the inhibition factor to $\beta$-catenin. From this, we infer that it is partially related to the occurrence of ameloblastomas.

The authors declare no conflict of interest.

The study protocol was approved by the National Nature Science Foundation of China (30672332).

\section{References}

1. Luo HY, Li TJ. Odontogenic tumors: a study of 1309 cases in a Chinese population. Oral Oncol 2009; 45: 706-11.

2. Sailer HF, Tarawneh F, Fourkas P, Antoniades DZ, Athanasiou AE. Surgical, orthodontic and prosthodontic rehabilitation of a patient with follicular ameloblastoma: a case report. Eur J Dent 2010; 4: 192-6.

3. Adekeye EO, Lavery KM. Recurrent ameloblastoma of the maxillofacial region. Clinical features and treatment. J Maxillofac Surg 1986; 14: 153-7.

4. Ghandhi D, Ayoub AF, Pogrel MA, MacDonald G, Brocklebank LM, Moos KF. Ameloblastoma: a surgeon's dilemma. J Oral Maxillofac Surg 2006; 64: 1010-4.

5. Carlson ER, Marx RE. The ameloblastoma: primary, curative surgical management. J Oral Maxillofac Surg 2006; 64: 484-94.

6. Yazdi I, Seyedmajidi M, Foroughi R. Desmoplastic ameloblastoma (a hybrid variant): report of a case and review of the literature. Arch Iran Med 2009; 12: 304-8.

7. Shahidi Sh, Bronoosh P, Daneshbod Y. Follicular ameloblastoma presenting as a sinonasal tumor. Iran Red Crescent Med J 2012; 14: 113-6.

8. Sarkar L, Sharpe PT. Inhibition of Wnt signaling by exogenous Mfrzb1 protein affects molar tooth size. J Dent Res 2000; 79: 920-5.

9. Xu HT, Wang L, Lin D, Liu Y, Liu N, Yuan XM, Wang EH. Abnormal betacatenin and reduced axin expression are associated with poor differentiation and progression in non-small cell lung cancer. Am J Clin Pathol 2006; 125: 534-41.

10. Kühl M, Sheldahl LC, Park M, Miller JR, Moon RT. The Wnt/Ca2+ pathway: a new vertebrate Wnt signaling pathway takes shape. Trends Genet 2000; 16: 279-83.

11. MacDonald BT, Tamai K, He X. Wnt/beta-catenin signaling: components, mechanisms, and diseases. Dev Cell 2009; 17: 9-26.

12. Harris ES, Nelson WJ. Adenomatous polyposis coli regulates endothelial cell migration independent of roles in beta-catenin signaling and cell-cell adhesion. Mol Biol Cell 2010; 21: 2611-23.

13. Ehebauer MT, Arias AM. The structural and functional determinants of the Axin and Dishevelled DIX domains. BMC Struct Biol 2009; 9: 70.

14. Lammi L, Arte S, Somer M, Jarvinen H, Lahermo P, Thesleff I, Pirinen $\mathrm{S}$, Nieminen P. Mutations in AXIN2 cause familial tooth agenesis and predispose to colorectal cancer. Am J Hum Genet 2004; 74 : 1043-50.

15. Wong ML, Medrano JF. Real-time PCR for mRNA quantitation. Biotechniques 2005; 39: 75-85.
16. Scharl A, Vierbuchen M, Conradt B, Moll W, Würz H, Bolte A. Immunohistochemical detection of progesterone receptor in formalin-fixed and paraffin-embedded breast cancer tissue using a monoclonal antibody. Arch Gynecol Obstet 1999; 247: 63-71.

17. Ozawa M, Baribault H, Kemler R. The cytoplasmic domain of the cell adhesion molecule uvomorulin associates with three independent proteins structurally related in different species. EMBO J 1989; 8: 1711-7.

18. Miyoshi Y, Iwao K, Nagasawa Y, et al. Activation of the beta-catenin gene in primary hepatocellular carcinomas by somatic alterations involving exon 3. Cancer Res 1998; 58: 2524-7.

19. Hashizume R, Koizumi H, Ihara A, Ohta T, Uchikoshi T. Expression of beta-catenin in normal breast tissue and breast carcinoma: a comparative study with epithelial cadherin and alpha-catenin. Histopathology 1996; 29: 139-46.

20. Hassanein AM, Glanz SM, Kessler HP, Eskin TA, Liu C. beta-Catenin is expressed aberrantly in tumors expressing shadow cells. Pilomatricoma, craniopharyngioma, and calcifying odontogenic cyst. Am J Clin Pathol 2003; 120: 732-6.

21. Sekine S, Sato S, Takata T, et al. Beta-catenin mutations are frequent in calcifying odontogenic cysts, but rare in ameloblastomas. Am J Pathol 2003; 163: 1707-12.

22. Kitagawa M, Hatakeyama S, Shirane M, et al. An F-box protein, FWD1, mediates ubiquitin-dependent proteolysis of beta-catenin. EMBO J 1999; 18: 2401-10.

23. Aulehla A, Wehrle C, Brand-Saberi B, Kemler R, Gossler A, Kanzler B, Herrmann BG. Wnt3a plays a major role in the segmentation clock controlling somitogenesis. Dev Cell 2003; 4: 395-406.

24. Leung JY, Kolligs FT, Wu R, Zhai Y, Kuick R, Hanash S, Cho KR, Fearon ER. Activation of AXIN2 expression by beta-catenin-T cell factor. A feedback repressor pathway regulating Wnt signaling. J Biol Chem 2002; 277: 21657-65.

25. Jernvall J, Thesleff I. Reiterative signaling and patterning during mammalian tooth morphogenesis. Mech Dev 2000; 92: 19-29.

26. Hughes TA, Brady HJ. Regulation of axin2 expression at the levels of transcription, translation and protein stability in lung and colon cancer. Cancer Lett 2006; 233: 338-47.

27. Dale TC. Signal transduction by the Wnt family of ligands. Biochem J 1998; 329 (Pt2): 209-23.

\section{Address for correspondence}

\section{Ming Zhong}

Oral Pathology Department

Oral Medicine College of China Medical University

Shenyang, China 110001

tel. $+86-24-13940502858$

fax +86-24-83285482

e-mail: zhongmingkouqiang@163.com

Submitted: $\quad 1.10 .2012$

Accepted: $\quad 24.10 .2012$ 